\title{
Thyroid Gland Hyperfunctioning Adenoma
}

National Cancer Institute

\section{Source}

National Cancer Institute. Thyroid Gland Hyperfunctioning Adenoma. NCI Thesaurus.

Code C46122.

A thyroid gland adenoma producing thyroxin. It is associated with hyperthyroidism.

Radioactive iodine scan reveals a hot nodule. 